\title{
Max Weber, as Múltiplas Modernidades e a Reorientação da Teoria Sociológica*
}

\author{
Wolfgang Knöbl
}

\section{INTRODUÇÃO}

Е inegável que muitas idéias dos clássicos da sociologia, os chamados "pais fundadores" da disciplina, têm sido cada vez mais pressionadas pelos argumentos dos sociólogos ligados ao campo do pensamento pós-moderno, aos estudos pós-coloniais ou aos estudos subalternos. Estes argumentos, nem sempre convincentes, são às vezes superficiais, outras vezes irrelevantes e com freqüência mais destrutivos do que construtivos. Mas não se pode negar que alguns acertam o alvo e, com isso, a vertente macrossociológica das grandes teorias vem sendo submetida a crescente e rápido descrédito. Em virtude desses ataques críticos, as descrições de Max Weber sobre a história e o desenvolvimento excepcional das sociedades ocidentais parecem-nos hoje cada vez menos convincentes. Mas isso não quer dizer que os instrumentos analíticos de Weber e de outros pensadores clássicos devam tornar-se necessariamente inúteis e sem sentido. Muito pelo contrário, estou certo de que os textos clássicos, a pesar de suas inúmeras distorções e preconceitos etnocêntricos e eurocêntricos, ainda nos podem ensinar a fazer boas pesquisas macrossociológicas. Mas essa afirmativa somente se tornará convincente quando nos dispusermos a confrontar séria e

\footnotetext{
*[A tradução do original em inglês "Max Weber, Multiple Modernities and the Re-Orientation of Sociological Theory" é de Vera Pereira.]

DADOS - Revista de Ciências Sociais, Rio de Janeiro, Vol. 49, nº3, 2006, pp. 483 a 509.
} 
cautelosamente os fatos históricos, metodológicos e teóricos com as grandes narrativas canônicas.

Assim, o termo "reorientação" citado no título deste ensaio não indica de modo algum um apoio incondicional à tentativa de Andre Gunder Frank de dar nova orientação a todo o programa da ciência social ocidental e, por conseguinte, renunciar à maior parte das obras da sociologia clássica em virtude de seu inerente viés etnocêntrico (Frank, 1998; 2004). Os argumentos holísticos radicais de Frank (ele simplesmente declara que existe um sistema econômico mundial e que todo o resto tem de ser analisado em função deste sistema) e seu patente materialismo, que reduz as instituições, a cultura, as ações e tudo mais a epifenômenos das estruturas da economia mundial, jogam fora a criança junto com a água do banho, por assim dizer, e ficam muito aquém dos insights válidos dos textos clássicos; o resultado disso é o enfraquecimento dos aspectos persuasivos da argumentação que ele nos oferece. Em vez de jogar no lixo da história a teoria sociológica clássica, meu artigo tem uma intenção mais modesta: fazer uma reflexão sobre as conseqüências metodológicas para a teoria macrossociológica da produção recente sobre a história da Europa e da China. Pergunto-me de que maneiras os cientistas sociais deveriam estruturar seus argumentos em face dos novos produzidos pela pesquisa histórico-sociológica recente, se realmente desejam participar de modo metodologicamente defensável do debate acerca das "múltiplas modernidades". Considerando que a tese das "múltiplas modernidades", defendida com tanta veemência pelas idéias de Shmuel N. Eisenstadt, inspira-se visivelmente no projeto intelectual de Max Weber, pretendo argumentar também que justamente esse tipo de sistematização metodológica é a maneira mais fecunda de descobrir o que ainda é defensável nos estudos sociológicos clássicos - e o que não é!

\section{VARIÁVEIS E CASOS}

Começarei com algumas observações sobre o premiado estudo histórico a respeito da chamada "ascensão do Ocidente", publicado por Michael Mitterauer, em 2003, na Alemanha ("Warum Europa? Mittelalterliche Grundlagen eines Sonderwegs"; uma tradução aproximada seria: "Por que a Europa? Origens Medievais de uma Via Excepcional"), que se alinha claramente a uma tradição de estudos originada em Max Weber ou mesmo em épocas anteriores nos séculos XVIII e XIX, quando os historiadores e cientistas sociais começaram a tratar te- 
oricamente das causas do evidente (!) domínio econômico, político e militar da Europa no mundo. Entre os estudos recentes nessa linha de análise, publicados antes do estudo de Mitterauer, devem ser mencionados os de Eric Lionel Jones (1981), John A. Hall (1985) e David Landes $(1998)^{1}$. O livro de Mitterauer, admiravelmente bem escrito, filia-se à mesma tradição, de modo que a estrutura de sua argumentação é muito semelhante à dos demais. Segundo esse autor, é possível detectar a existência de uma longa cadeia causal de vários fatores que remonta pelo menos à Idade Média. Mitterauer refere-se, por exemplo, à existência na Europa de um tipo particular de agricultura, que diferenciou positivamente essa parte do mundo; ressalta a existência de uma estrutura familiar típica da Europa Central e Ocidental que deve ter promovido uma excepcional mobilidade geográfica e um grau incomum de individualismo; faz referência a uma forma especial de feudalismo, que parece ter dado origem a modos democráticos de participação; e ressalta o papel da Igreja católica, as conseqüências da imprensa e outros fatores.

À primeira vista, o argumento geral parece bastante plausível, principalmente porque, como historiador, Mitterauer apresenta uma enorme quantidade de fatos que os cientistas sociais dificilmente conseguem questionar, e, mais ainda, porque ele adota uma argumentação multicausal que rejeita, de modo enérgico e convincente, as ambições reducionistas tanto dos francamente materialistas quanto dos francamente culturalistas. Creio que o livro de Mitterauer é uma interpretação histórica e sociológica muito bem realizada. No entanto, a despeito de todos os argumentos arrolados na tese da "ascensão do Ocidente", duas debilidades parecem-me particularmente evidentes: uma de ordem metodológica, outra de ordem empírica.

O problema metodológico pode ser resumido na frase: "Variáveis demais, casos de menos!" (Lijphart, 1971; Lieberson, 1991; King, Kehoane e Verba, 1994). A explicação de Mitterauer sobre a "ascensão do Ocidente" - como a de todos os autores dessa linha de pensamento - é em certo sentido sobredeterminada. Na opinião de Mitterauer, todos os fatores anteriormente citados parecem ter efetivamente impulsionado o Ocidente a seguir uma via peculiar que se acabou revelando vitoriosa. Mas levando em conta que somente umas poucas civilizações podem ser usadas como pontos de referência comparativos aceitáveis para uma explicação dessa ordem (provavelmente a Índia, a China e algumas regiões importantes do Islã), é claro que, por definição, também é 
quase impossível avaliar ou cotejar os fatores mencionados. Assim, adotando-se uma estratégia de pesquisa baseada em tão poucos casos, jamais saberemos quais fatores causais apontados por Mitterauer (Igreja católica, feudalismo, tipos de família etc.) são suficientes ou necessários, e quais seriam inclusive inúteis para a explicação da "ascensão do Ocidente". Uma estratégia de pesquisa que tem cinco, seis ou mais variáveis e apenas três ou quatro casos arrisca-se a produzir resultados arbitrários, isto é, os seguidores dessa tradição analítica, como Mitterauer e outros - como poderia alegar uma crítica baseada na chamada "small-N-research" [pesquisa centrada em pequeno número de casos] - até poderiam contar uma boa história, mas tudo ficaria dependendo da predisposição do público a querer ou não acreditar nela ${ }^{2}$.

O problema do pequeno número de casos aflige muitos projetos de pesquisa macrossociológica que não usam métodos quantitativos, mas é especialmente incômodo para a pesquisa comparativa de civilizações que segue o paradigma das "múltiplas modernidades", já que parece ser bastante difícil em tais condições elaborar uma estratégia de investigação convincente e metodologicamente correta pelo simples fato de que não há muitas civilizações a analisar. A situação agrava-se quando os cientistas sociais, nas suas buscas de causas, recuam ainda mais no tempo histórico do que Mitterauer: Shmuel N. Eisenstadt, por exemplo, faz de sua tentativa de teorizar a "era axial" o ponto de partida para o estudo das civilizações. Nesse caso, poder-se-ia inclusive descobrir variáveis independentes mais "relevantes" que as de Mitterauer, o qual recuou "tão-somente" ao ano 1000 a.C. Assim, a proposta de Eisenstadt de pesquisar períodos anteriores a Cristo piora ainda mais o problema metodológico. Ao que me consta, até hoje nenhuma discussão rigorosa foi feita sobre as conseqüências do problema do pequeno número de casos para a análise de civilizações ou para o debate das "múltiplas modernidades", uma discussão que, no entanto, me parece indispensável se realmente quisermos estabelecer uma sólida tradição de pesquisa nessa área. Na minha opinião, em princípio, só há quatro soluções para o problema do pequeno número de casos, soluções que, no entanto, são muito diferentes quanto ao grau de satisfação que poderiam proporcionar a um pesquisador metodologicamente refinado ou a um defensor "ortodoxo" daquele paradigma. Vejamos:

1) É possível manter-se fiel ao paradigma civilizacional e ao mesmo tempo ser metodologicamente correto se nos dispusermos a aumentar 
o número de casos por meio da construção de vários períodos de tempo em que as variáveis independentes e os resultados sejam exaustivamente analisados. Seguir essa estratégia significa não só comparar a Europa, a Índia, a China e o mundo islâmico em geral, mas também todas essas civilizações em diversas fases ou "estágios" da história de cada uma, o que por si só serviria para aumentar o número de casos ou observações e aperfeiçoar a estratégia geral de pesquisa. Mas pelo que sei, essa estratégia ainda não foi submetida a um teste sistemático, embora sua viabilidade tenha sido demonstrada pelo menos por alguns historiadores. Se R. Bin Wong (1997), por exemplo, compara a história da China e a da Europa Ocidental em momentos diversos e examina se nesses períodos houve diferenças ou semelhanças nas formas de construção do Estado [state-building], nas estruturas familiares (as variáveis independentes) e diferenças significativas ou não nos resultados econômicos (a variável dependente), pode-se considerar a estrutura do livro de Wong como uma tentativa de aumentar o número de casos mediante a subdivisão do período examinado. Ainda que esse tipo de estratégia metodológica pareça muito fácil e simples, suas dificuldades não devem ser subestimadas, já que freqüentemente ela exige um conhecimento profundo e sólido de fases históricas, muitas vezes bastante diferentes, de duas ou mais civilizações. Na verdade, Wong demonstrou que, até o início do século XIX e durante longos períodos, a variável dependente (as estruturas de mercado) eram bem parecidas na China e na Europa Ocidental, se bem que a variável independente (as estruturas do Estado, por exemplo) variassem muito não só entre as duas civilizações mas na história de cada uma.

2) A estratégia de pesquisa também pode ser aperfeiçoada se relaxarmos um pouco a estrutura teórica da análise comparativa ou do discurso das "múltiplas modernidades". É certamente possível, no caso de algumas questões de pesquisa, comparar regiões (Szücs, 1988) entre e dentro de civilizações diversas, o que também permite aumentar o número de casos sob observação. Por exemplo, em vez de falar sobre uma civilização "americana" (que quase sempre subentende os Estados Unidos da América), talvez seja mais útil fazer uma distinção entre o Norte e o Sul dos Estados Unidos ${ }^{3}$, ou, em vez de falar de duas Américas (do Norte e Latina), tentar agrupar as regiões que cortam fronteiras, tão pouco valorizadas por tanto tempo. Ou então, por que não juntar o Sul dos Estados Unidos com partes do Caribe, da América Central (Townsend, 2000) ou da América do Sul, de acordo com as semelhanças de seus padrões iniciais de imigração ou de suas estruturas econômi- 
cas, já que todas ou a maioria dessas "regiões" se basearam em economias de plantation? Quanto à Europa: por que comparar a Europa ou a Europa Ocidental em seu conjunto com a China e não com partes da Inglaterra ou com a região do delta do Yangzi*, como sugeriu Kenneth Pomeranz (2000)? A explicação é que o caso europeu inclui subcasos tão completamente diferentes entre si que generalizações amplas não fazem sentido.

Esses procedimentos nos permitiriam elevar o número de casos e observações, mas convém ter em mente que não é essa a estratégia comumente utilizada por Eisenstadt e seus seguidores, e por uma razão muito simples: a introdução da palavra "região", ou seja, da pesquisa sobre regiões de modo geral, não se adapta a uma forma de análise que normalmente estrutura seus casos (isto é, civilizações) em termos culturais ou religiosos. Trazer as regiões de volta ao debate poderia desmontar o eixo teórico mais importante do pensamento de Eisenstadt: o conceito cultural e religioso de uma "era axial", estreitamente associada à noção de civilizações. E como "regiões de importância histórica às vezes se caracterizam por constelações multicivilizacionais duradouras" (Arnason, 2004), essa é mais uma sugestão de que "regiões" e "civilizações" são conceitos difíceis de relacionar um com o outro. Entretanto, reinserir o conceito de regiões pode ser uma das soluções mais promissoras para o aperfeiçoamento da condição metodológica da análise de civilizações ${ }^{4}$.

Concentrar a análise em comparações sistemáticas entre países ou Estados-nações em civilizações pode ser uma solução alternativa. Só que isso acabaria desarticulando todo o paradigma civilizacional e todo o discurso sobre as "múltiplas modernidades", já que esses conceitos introduzem uma relação não resolvida entre, de um lado, os países e, de outro, as civilizações. E logo viria à mente esta embaraçosa pergunta: por que você está usando o modelo teórico civilizacional se, na realidade, sua análise faz uma comparação sociológica tradicional que considera os Estados-nações como unidades comparativas básicas? Além disso, a alternativa tornaria insólito o trabalho de teorização das múltiplas modernidades, porque se o pesquisador usar os Estados nacionais como unidades de análise, acabará se deparando com dezenas ou mesmo centenas de trajetórias distintas para a modernidade - um resulta-

* Transcrição pinyin para Yang-tsé. (N. do E.) 
do que certamente não era o que esperavam inicialmente os criadores daquele paradigma.

3) Outra possibilidade é rejeitar por completo as ambições explicativas e limitar-se à mera descrição com a pura e simples finalidade de contrastar civilizações, comparando-as somente com o intuito de individualizá-las. Esta parece ter sido a escolha de Shalini Randeria (Conrad e Randeria, 2002) para estudar o "entrelaçamento" [entanglement] de modernidades. O objetivo da autora não é tanto o de explicar a lógica endógena dos processos sociais em várias civilizações; na realidade, Randeria não acredita na existência de nenhuma lógica endógena, e sua intenção é antes a de explicar teoricamente o impacto recíproco das civilizações, sem afirmar muita coisa sobre as causas necessárias ou suficientes dos processos que geraram no passado conseqüências culturais, políticas e econômicas.

Essa estratégia cautelosa e modesta parece ser bastante conveniente, porque, na realidade, seria extremamente difícil cotejar todos os fatores e variáveis endógenos e exógenos envolvidos nas situações, uma estratégia seguida não só por Randeria, como também pelos historiadores que se reúnem sob o rótulo de "histoire croisée" (cf. Werner e Zimmermann, 2002). Porém, alguns pesquisadores consideram que essa estratégia exclusivamente descritiva não é suficientemente rigorosa para a ciência social, porque incorre em outras dificuldades tão grandes quanto as que afligem a análise comparativa tradicional de civilizações. Um dos argumentos críticos pelo menos me parece fundamental: é sem dúvida correto sugerir que raramente se encontram entidades isoladas, como as nações ou as civilizações. Estas "entidades" são quase sempre influenciadas por fatores externos, o que traz à discussão o problema de Galton (cf. Tenbruck, 1992): se os casos em observação (digamos, civilizações como os Estados Unidos e a Europa, ou a Europa e a China) influenciam uns aos outros, então qualquer comparação entre eles se tornará passível de um viés sistemático, e as asserções causais serão praticamente inúteis. A esse respeito, pode-se dizer que o método comparativo no campo da macrossociologia é uma ferramenta muito problemática, simplesmente porque, insisto em dizer, não há casos isolados. Levando tudo isso em conta, poderíamos concluir que o melhor é abandonar de todo o método comparativo, conforme, aliás, já foi sugerido por alguns pesquisadores (cf. Magubane, 2005). Mas a questão é saber se essa conclusão é de fato inteligente, por um motivo: falar de influências ou impactos (externos) pressupõe a 
idéia de que há "alguma coisa" influenciada, algo que sofre um impacto. E para determinar essa estranha "coisa", que, evidentemente, não é um dado como parecem crer os empiristas e os positivistas, é preciso fazer comparações. Definir fenômenos sociais implica compará-los, significa construir - mediante comparações - tipos ideais, como propôs Weber. Assim, no final das contas, é impossível evitar o método comparativo, ainda que haja consciência de que usar tal método para fazer afirmações causais é um empreendimento espinhoso, visto que o problema de Galton quase sempre se insinua nas ciências sociais.

4) O problema de variáveis demais e casos de menos também poderia ser resolvido por uma estratégia completamente diferente: reduzir o número de variáveis, pura e simplesmente. Sem querer chegar a uma solução tão grosseira, eu diria que, em princípio, a análise comparativa de civilizações de Eisenstadt é uma tentativa ousada de caminhar nessa direção. O que Eisenstadt faz - e minha descrição de sua estratégia de pesquisa certamente tende agora a um simplismo excessivo, e por isso mesmo injusto - é estruturar as civilizações em torno de um núcleo religioso ou cultural, afirmando que, no final das contas, esse núcleo é justamente o causador da variação dos processos entre civilizações diferentes e da peculiar configuração de suas instituições ${ }^{5}$. Mas essa solução também apresenta seus problemas. Abstraindo a crítica de que a estratégia de pesquisa de Eisenstadt tem muitos pontos de contato com uma abordagem idealista ou culturalista, podemos pelo menos alegar que as investigações históricas realizadas nos últimos 10 ou 15 anos, mencionadas no começo deste artigo, vêm tornando seus procedimentos ainda mais problemáticos, por duas razões principais: a) o debate sobre a "era axial" já chegou a um ponto em que toda a idéia corre o risco de se tornar difusa, como afirmou Peter Wagner (2005) ${ }^{6}$. Além disso - citando novamente Wagner-, é preciso estar consciente de que talvez pareça bastante inusitado falar em uma via européia quando se constataram tantas mudanças de direção nesse caminho durante vários períodos históricos. Os insights gerados por certa inovações axiais, como a reflexividade, a historicidade e outros, foram repetidas vezes perdidos e redescobertos durante a história da Europa, de modo que não é convincente os transformar em traços culturais e, portanto, em conquistas da era axial, isto é, em momentos definidores da Europa; b) a idéia emanada da historiografia recente de que até o século XVIII a Índia e a China, por exemplo, eram tão ou mais dinâmicas e economicamente desenvolvidas que a Europa tem certa relação com o último argumento e nos induz a um mergulho no campo das questões empíri- 
cas, mas não obscurece um problema metodológico que salta aos olhos. Se essas descobertas empíricas forem corretas, se a divergência econômica entre a Europa e a China somente se tornaram visíveis depois do século XVIII, não tem muita lógica realçar a importância fundamental de especificidades religiosas que se originaram há 200 anos para explicar tais diferenças. Esse argumento é obviamente relevante para Eisenstadt, mas também o é para Weber, que se vale de uma explicação semelhante ao analisar as estruturas do passado chinês remontando até o tempo de Confúcio (Weber, 1951).

Recapitulando essa discussão metodológica, um debate crítico sobre a tese das "múltiplas modernidades" e, acima de tudo, do paradigma civilizacional terá de considerar alguns dos argumentos discutidos no ponto 4. Mais concretamente, estou convencido de que o tipo de pesquisa histórica, ou histórico-sociológica, sobre a dinâmica de áreas não-européias mencionadas anteriormente vai ter um grande impacto nas análises macrossociológicas vinculadas à tradição do paradigma das "múltiplas modernidades", na tradição de Eisenstadt e de Weber. Por isso, gostaria de fazer algumas indicações acerca da importância do conteúdo empírico de alguns estudos publicados nos últimos 15 anos. Desenvolverei a idéia de que é possível detectar uma certa lógica nessa discussão histórica, uma lógica que nos fornecerá algumas pistas sobre os caminhos e os trajetos adequados a uma análise macrossociológica no futuro próximo.

\section{HISTÓRIA E MACROSSOCIOLOGIA}

O conhecido livro de Janet Abu-Lughod, Before European Hegemony: The World System A. D. 1250-1350 (Abu-Lughod, 1989), contém uma das mais importantes críticas ao paradigma de Eisenstadt; na verdade, o livro analisa criticamente a maioria das interpretações propostas pelo debate sobre a "ascensão do Ocidente" que consideram fatores culturais ou religiosos, muito distantes na dimensão histórica, como variáveis de grande importância para a explicação de processos mais ou menos contemporâneos. Essa observação é surpreendente porque o objetivo original da obra de Abu-Lughod era contribuir para a discussão sobre a teoria dos sistemas mundiais dominada com tanto brilhantismo por Immanuel Wallerstein. Já que Wallerstein e seus seguidores diziam estar na periferia heterodoxa do centro ortodoxo da macrossociologia, não se esperava que Before European Hegemony tivesse tamanho impacto sobre a macrossociologia ortodoxa. Mas os argumentos de 
Abu-Lughod imediatamente levaram todo o debate macrossociológico a um novo patamar, pois seu livro também podia ser visto como uma crítica persuasiva ao pensamento histórico-sociológico predominante.

É verdade, porém, que o primeiro alvo dos ataques de Abu-Lughod foi a descrição de Wallerstein de determinados períodos históricos e, principalmente, a maneira como ele estabeleceu diferenças entre certos períodos. A autora não critica o núcleo teórico de Wallerstein, desenvolvido com base em Karl Marx, Fernand Braudel e - às vezes - Talcott Parsons; ela simplesmente defende que a história da economia mundial deve ser contada de maneira diferente. O primeiro argumento histórico da autora é que não havia nenhuma diferença significativa entre as economias dos séculos XIII e XVI, nem na Europa nem na Ásia. Dessa forma, a tese de Wallerstein de que o estágio da hegemonia européia foi estabelecido no século XVI não tem muito sentido. De acordo com Abu-Lughod, Wallerstein ainda dá um crédito excessivo à idéia weberiana de que algo economicamente muito importante deveria ter acontecido nesse século. Porém, a autora não conseguiu descobrir esse "acontecimento" de tamanha importância.

“Um fundamento empírico para a distinção entre períodos 'modernos' e períodos 'tradicionais' poderia ser a diferença entre sociedades organizadas para a produção de mercado, que não separam a propriedade do capital da propriedade da força de trabalho, e as sociedades que não fazem essa separação. Mas uma inspeção minuciosa revela que essa distinção não se sustenta, porque o trabalho livre e a monetização da troca existiram muito antes da 'moderna produção industrial', o trabalho escravo e o escambo persistiram durante boa parte da era moderna e provavelmente nunca houve uma sociedade urbana em que os 'proprietários' não tivessem obrigações ou responsabilidades" (idem:9-10, ênfases no original).

O segundo argumento da autora foi que desde antes do século XVI já havia um outro sistema mundial, que se estendia do Leste asiático até uma pequena e insignificante península ocidental da Ásia denominada Europa. Era um sistema mundial multipolar, ao contrário do conceito de sistemas mundiais de Wallerstein, isto é, um sistema não-centrado na Europa e dominado por cidades, não por Estados ou cidadesEstados. A conseqüência imediata dessa percepção foi a de pôr em dúvida a plausibilidade das hipóteses sobre a existência de uma diferença 
significativa entre as formas de produção e comércio européias e asiáticas:

"[...] apesar da tendência dos historiadores ocidentais que lidam com o tema da 'ascensão do Ocidente' de enfatizar as características excepcionais do capitalismo ocidental, o exame comparativo das instituições econômicas revela enormes similaridades $e$ paralelos entre as formas de capitalismo asiática, árabe e ocidental" (idem:15, ênfases no original).

Para este artigo, não é tão importante saber como Abu-Lughod explica as circunstâncias da marcha da Europa rumo ao poder mundial desde então (ela cita fatos contingentes como a peste negra e a crise econômica chinesa do século $\mathrm{XV}$, que proporcionaram à Europa uma oportunidade de preencher o espaço vazio); o que de fato importa é o que se pode inferir do quadro histórico global desenhado por ela. Isso porque, se o relato histórico de Abu-Lughod for verdadeiro, então as explicações de Eisenstadt a respeito dos processos dinâmicos peculiares da Europa e do Oriente Médio - processos que em princípio já podiam ser constatados durante a "era axial", quando determinados sistemas de crença do mundo judaico-cristão criaram a possibilidade de uma rápida mudança cultural e institucional - evidentemente perdem credibilidade. Os argumentos da autora tornam menos plausível a hipótese do caráter excepcional da Europa, com sua peculiar formação religiosa (ou diversidade de formações religiosas), desde os primórdios de seu desenvolvimento, enquanto, por outro lado, seu papel na política mundial e na esfera da economia continuou marginal ou periférico até o século XVI, pelo menos.

Os argumentos de Abu-Lughod, que enfatizam a existência de um sistema mundial antes do século XVI e a posição marginal da Europa neste sistema, parecem atingir em cheio as explicações teóricas de Wallerstein e de Eisenstadt, mas não são tão eficazes no que respeita a alguns aspectos da obra de Weber. Afinal, os weberianos, especialmente os defensores da tese da "ética protestante", sempre podem alegar que as conseqüências não só da ética protestante, como das mudanças político-institucionais iniciadas pela Reforma, muitas vezes somente se efetivaram décadas ou séculos depois. Portanto, ainda que Abu-Lughod esteja certa ao afirmar que não havia uma grande diferença nos capitalismos dos séculos XIII e XVI, isso por si só não afeta o argumento de Weber de que pelo menos as "sementes" da modernidade na Europa 
devem ser detectadas na era da Reforma européia. Como a autora não disse muita coisa sobre o período posterior à Reforma, depois desse nefasto século XVI, a tese de Weber ou proposições similares relacionadas com a tradição da "ascensão do Ocidente" ainda poderiam se sustentar.

Mas é curioso que o debate não tenha parado por aí, porque alguns sociólogos e especialmente historiadores da economia demonstraram que, do ponto de vista econômico, a Índia e a China algumas vezes estiveram à frente da Europa bem depois do século XVI. Jack A. Goldstone (2000) denominou de "escola da Califórnia" o grupo de autores empenhados especificamente nesse debate, pois "a maioria deles pertence a universidades desse Estado". Não estou muito convencido da utilidade dessa designação, porque os enfoques metodológicos dos pesquisadores desse grupo variam muito. Entretanto, as contribuições dos historiadores desse grupo são importantes e altamente pertinentes para o questionamento das teses weberianas que situam o momento inicial do desenvolvimento excepcional da Europa nos séculos XVI, XVII ou mesmo XVIII. Na minha opinião, pelo menos dois desses historiadores, já citados aqui, são muito importantes nesse contexto: R. Bin Wong e Kenneth Pomeranz.

Wong (1997) discute a própria noção de "capitalismo" e indaga se o conceito pode representar por si só um obstáculo ao entendimento adequado dos processos que conduziram à chamada "decolagem" industrial da Inglaterra e ao caminho divergente tomado pela China (e Índia) na mesma época, a virada do século XVIII para o século XIX. É preciso levar em conta, adverte Wong, que os economistas clássicos de Adam Smith a David Ricardo e T. Robert Malthus - eram filhos de seu tempo, de modo que não trataram de processos econômicos gerais, mas daqueles que ocorreram durante o período (pré-industrial) em que eles viveram. Todos três acreditaram firmemente - não sem razões plausíveis - que o crescimento econômico não é infinito, já que a dinâmica dos salários está ligada a processos demográficos e um certo tipo de esgotamento de recursos naturais deve ser esperado. Em todas as economias pré-industriais, tanto na Europa como na China imperial, os observadores tiveram experiência semelhante.

"A China e a Europa Ocidental compartilhavam um mundo de colheitas incertas e limitações materiais. Ambas passaram por ciclos de expansão e contração econômica, que progressivamente engendraram 
grandes economias impulsionadas por uma dinâmica smithiana similar de divisões espaciais do trabalho e vantagens comparativas por intermédio do mercado" (idem:31-32).

Portanto, Smith, Ricardo e Malthus formularam teorias sobre o crescimento econômico e os processos dinâmicos, mas não acreditavam que esses processos fossem infinitos ou ilimitados. O que eles não sabiam, pois tinham um conhecimento limitado da Ásia, era que suas descobertas também podiam ser constatadas na China. Algumas regiões desta eram muito dinâmicas economicamente, para dizer o mínimo. Conforme observaram alguns historiadores, na China ocorreu inclusive uma espécie de desenvolvimento proto-industrial no mesmo período que na Europa, especialmente na região do delta do rio Yangzi. Assim, Smith, Ricardo e Malthus poderiam ter descrito na China os mesmos processos dinâmicos, inclusive uma proto-industrialização, só que esses processos eram limitados pela quantidade de energia disponível.

Se isso for verdade, pode-se concluir que o crescimento econômico em si, mesmo as estruturas e processos proto-industriais, não podem ser precondições decisivas para a industrialização propriamente dita. Tanto a China quanto a Europa Ocidental passaram pela experiência de um enorme crescimento em determinadas áreas proto-industriais, mas somente na Europa ocorreu a "decolagem". O argumento de Wong é que o salto industrial europeu e seu surpreendente avanço em relação à China foram resultados de acontecimentos mais ou menos imprevisíveis, e não conseqüências de um processo contínuo e ininterrupto de transição de uma fase de crescimento proto-industrial para uma fase de industrialização "de verdade".

\footnotetext{
"A capacidade de a dinâmica industrial de 1900 possibilitar a criação de uma riqueza material inimaginável em 1800 torna difícil acreditar que a industrialização evoluiu naturalmente de uma dinâmica pré-industrial. Por esse motivo, a Revolução Industrial conserva um significado que certas pesquisas sobre a industrialização tenderam a obscurecer, se não a anular, ao enfatizarem a mudança gradual" (idem:49).
}

Wong, então, exorta o leitor a não fazer distinção entre pelo menos duas formas de capitalismo, e para isto vai buscar apoio na análise de E. A. Wrigley (1988) sobre a Revolução Industrial. Em seu estudo, Wrigley estabelece um claro contraste entre uma "economia orgânica" 
(pré-industrial), de um lado, e uma "economia baseada no mineral" (industrial), de outro lado; esta última logrou explorar o carvão e outros recursos minerais e, em conseqüência, aumentou o uso de energia a um nível até então inimaginável ${ }^{7}$. Assim, a ruptura com o passado não proveio de uma nova ética protestante (Weber) ou de formas peculiares de acumulação de capital (Marx), mas de descobertas tecnológicas, muitas vezes eventuais, que permitiram à Europa ultrapassar a Ásia:

"Para descobrir como a Europa escapou dessas limitações, temos de le-
var em conta [fatores ligados] a tecnologia ou as forças de produção. Se
um conjunto de mudanças tecnológicas sem precedentes não tivesse
ocorrido, as pressões da população sobre os recursos teriam aumenta-
do - a espécie de possibilidade que denominamos de malthusiana por
causa do enunciado sistemático de Malthus sobre esse perigo" (Wong,
1997:52).

Nota-se que para Wong a pergunta fundamental não é por que a economia chinesa estagnou no século XVIII (o que, de fato, aconteceu), mas por que a Europa, especialmente a Inglaterra, conseguiu romper o ciclo malthusiano. Essa pergunta está hoje no centro das pesquisas históricas comparativas, e é altamente contestada. Enquanto alguns autores, seguindo a linha de pensamento marxista, argumentam que a exploração do Novo Mundo pelas nações européias propiciou uma acumulação de capital suficiente para induzir a dinâmica industrial européia (Blaut, 1993) ${ }^{8}$, Wong não acredita nessa tese e afirma que ao fim e ao cabo essa exploração não superou a economia orgânica e estática da Europa (idem:49).

Em que pese sua relevância, não examinarei esse debate aqui. Muito mais importante é que Pomeranz (2000), em seu livro The Great Divergence: China, Europe and the Making of the Modern World Economy, provou com fatos a semelhança do desenvolvimento econômico da Europa e da China até o final do século XIX, e o fez de modo muito mais convincente do que qualquer outro pesquisador fizera antes, um argumento que, vale dizer, adquire uma certa plausibilidade pela leitura exclusiva de fontes européias contemporâneas, pois é sabido que os observadores europeus da China do século XVIII tinham uma opinião notoriamente elevada sobre a cultura, a tecnologia e a política chinesas (Osterhammel, 1998). Nessa época, a palavra "Oriente" ainda não havia se tornado depreciativa, e isso é compreensível porque os europeus não consideravam que a cultura e a riqueza material da China eram ím- 
pares no mundo. De qualquer maneira, a leitura de Pomeranz das fontes européias e chinesas demonstra claramente que, até o século XVIII, a estrutura do capitalismo asiático não diferia de maneira significativa da estrutura do capitalismo europeu. Por que então ocorreu uma "decolagem" na Europa e não na China? A razão pela qual a Europa conseguiu escapar da armadilha malthusiana e a China não (segundo Wong) devia-se a fatores contingentes, segundo Pomeranz, em boa parte relacionados com o colonialismo europeu nas Américas, onde os colonizadores aprenderam novas técnicas agrícolas que transferiram para seus países; além disso, a exploração das minas de prata das colônias proporcionou à Europa um enorme fluxo do metal precioso, o que permitiu aos europeus participarem dos sistemas de comércio asiáticos possibilidade inexistente até então, pois, excetuando a prata, a Europa não tinha muito mais a oferecer aos seus parceiros comerciais da Ásia9 .

Recapitulando os argumentos de Abu-Lughod, Wong e Pomeranz, e admitindo que, em essência, eles sejam bastante sólidos, podemos tirar duas conclusões que, surpreendentemente, parecem inverter as opiniões nesse antigo debate sobre a "ascensão do Ocidente". John M. Hobson (2004) descreveu-as com notável clareza:

"1. O Oriente possibilitou a ascensão do Ocidente pelo simples fato de que já tinha desenvolvido uma economia vital e expansiva, principalmente em infra-estruturas mercantis que se disseminaram no Ocidente e foram inteligentemente aproveitadas pela Inglaterra.

2. Não resta dúvida de que o Ocidente foi rápido na adoção dessas técnicas econômicas e se apropriou de recursos da Ásia e de outras partes do mundo. É uma façanha que não se deve negligenciar, com certeza, mas não chega nem perto das teses de Weber, Eisenstadt (ou de Mitterauer) a respeito de um desenvolvimento autônomo ou endógeno da Europa".

É evidente que nenhuma razão lógica nos obriga a deduzir exatamente essas opiniões, porque o debate sobre as "verdadeiras" causas do progresso industrial da Inglaterra ainda não chegou a uma conclusão. É preciso não esquecer, por exemplo, que os argumentos de Wong e Goldstone (ver nota 9) aludem a uma peculiaridade da cultura e da técnica na Inglaterra e, por conseguinte, não afirmam que a contribuição do Ocidente para sua própria ascensão deva ser negligenciada. Entretanto, os dados empíricos que Abu-Lughod, Wong, Pomeranz e muitos outros ${ }^{10}$ trouxeram à baila lançam nova luz não só sobre a questão da "ascensão do Ocidente", mas também sobre a discussão acerca das "múltiplas modernidades", dados que devem ter conseqüências meto- 
dológicas. Isso me leva de volta ao começo deste artigo e à discussão sobre o problema do pequeno número de casos. Os pesquisadores envolvidos nesse debate macrossociológico precisam levar em consideração pelo menos cinco pontos, se não quiserem se colocar em uma posição vulnerável aos argumentos de metodólogos refinados.

\section{CONCLUSÕES PROVISÓRIAS}

A título de conclusão, tentarei apresentar cinco pontos do modo mais claro e sistemático possível e advirto que essas idéias são importantes não só para uma explicação teórica da divergência de vias para o desenvolvimento na China e na Europa, mas também na América Latina e em outras regiões do mundo. Creio que essa questão deve ser ressaltada enfaticamente, porque, no contexto do debate sobre as "múltiplas modernidades", centrado empiricamente na Europa e na Ásia, o "resto" do mundo tende a ser esquecido pela sociologia, desfecho triste de uma discussão em que a América Latina já ocupou um lugar central.

1. Fazer análises comparativas de civilizações, segundo a versão grandiosa de Shmuel Eisenstadt, significa recomendá-la como uma forma perfeitamente legítima de teorização macrossociológica. É preciso saber, no entanto, que esse tipo de raciocínio permanecerá metodologicamente questionável enquanto o problema do pequeno número de casos não for resolvido de maneira adequada. Por isso não se deve ter ambições explicativas muito altas para uma análise dessa natureza. Recomendo, portanto, a adoção de uma estratégia que se limite a casos contrastantes ou que busque reconstituir o impacto de uma civilização sobre outra, como sugere Randeria (Conrad e Randeria, 2002). Em todo caso, uma análise civilizacional de grande fôlego deve ser cautelosa com as afirmações explicativas.

2. Se um pesquisador quiser ater-se ao paradigma civilizacional e fazer comparações entre civilizações no intuito explícito de propor uma explicação, apesar de todas as críticas metodológicas, ele não deve concentrar demasiadamente o foco em fatores e variáveis muito remotos no tempo; não só para não agravar o problema do pequeno número de casos, mas em proveito da plausibilidade empírica, pois é quase impossível desconsiderar os resultados das pesquisas históricas de Abu-Lughod, Wong e Pomeranz. Concentrar a atenção nas transformações da "era axial" não ajuda muito a explicar o fato de que a diver- 
gência de vias para o desenvolvimento na Europa e na China deu-se no século XVIII ou mesmo no XIX.

Pôr os argumentos sobre a "era axial" como pano de fundo para um esquema explicativo não quer dizer, porém, que as estruturas religiosas, as instituições religiosas, os sistemas de crença, as ideologias e tudo mais sejam inúteis para a explicação da "ascensão do Ocidente" ou da estagnação de outras civilizações nos séculos XVIII e XIX.É essa a inferência equivocada de Gunder Frank e de outros autores ligados ao campo da análise de sistemas mundiais. Uma análise de fundo reducionista (marxista) também não é muito útil para esse fim. O fato de ser quase impossível explicar os problemas de hoje aludindo a estruturas histórico-religiosas de mais de 2 mil anos atrás não significa que se deva ignorar completamente estruturas religiosas, políticas ou de outra natureza não-econômica. Ao contrário, creio que o programa de pesquisa de Shmuel Eisenstadt pode ser especialmente valioso para a interpretação de processos de mudança social em diferentes civilizações, porque somente a observação de fatores e contextos religiosos e culturais permitirá compreender configurações civilizacionais peculiares. Usando uma linguagem mais abstrata: em vez de abandonar a multicausalidade defendida por Weber (e por Eisenstadt), deve-se afirmar esse princípio como a mais importante estratégia para a análise das múltiplas modernidades. Mas eu gostaria de repetir o que afirmei anteriormente: a busca da causalidade não deve remontar muito longe na história. Ou seja, as análises que comparam civilizações distintas devem enfocar principalmente os últimos três ou quatro séculos. Essa recomendação me parece necessária não só por causa do já mencionado problema do pequeno número de casos, mas porque uma das tarefas mais urgentes da macrossociologia é explicar por que certas regiões da Europa Ocidental, sobretudo a Inglaterra, começaram a ultrapassar a China (e a Índia) que tinham, antes da Revolução Industrial, economias pelo menos tão avançadas quanto as da maioria ou mesmo de todos os países europeus na mesma época. Wong e Pomeranz, por exemplo, não me parecem propor explicações sólidas sobre essa divergência de trajetórias. Só que o foco principal de seus estudos não é esse enigma histórico.

Resta ver se a alusão de Goldstone a uma cultura científica peculiar à Inglaterra resiste ao teste do tempo ou se, como outros alegam, a chave do problema está no colonialismo europeu. Mas se houver a crença de 
que a teoria do colonialismo pode ajudar a entender o problema (e há algumas indicações de que essa pode ser uma boa solução), os participantes do debate sobre as "múltiplas modernidades" devem refletir no mínimo sobre dois pontos que dizem respeito aos padrões de migração e/ou à estrutura do Estado. Esses dois aspectos podem ajudar muito a elaborar a diferença entre a América do Norte como uma "civilização" e outras regiões das Américas:

a) Em que pese o conceito de "settler-societies" não estar hoje mais tão em voga quanto na década de 1960, quando Louis Hartz (1964) usou a expressão, parece-me que está voltando a se tornar atual, haja vista alguns estudos na área da história do meio ambiente (cf. Tyrrell, 2002), e há excelentes motivos para isso. A expansão européia propiciou a formação de diversos padrões de povoamento e de novos modos de fazer agricultura (economia de plantation versus sociedade de pequenos proprietários); trouxe, portanto, novas e diferentes formas de capitalismo, com enormes conseqüências não só para as áreas colonizadas como também para os países de origem dos colonizadores (Osterhammel, 2000). Esse aspecto dos encontros de civilizações foi muito pouco estudado pelos seguidores do paradigma das "múltiplas modernidades", e me parece merecer mais atenção. A reflexão sobre esses temas também recoloca em pauta a "América Latina" que ficou esquecida durante muito tempo nesse debate ${ }^{11}$.

b) Deve-se mencionar ainda o papel do Estado nesses processos de povoamento. Por que a Europa conseguiu colonizar o mundo e ganhar hegemonia nos séculos XVIII e XIX em comparação com rivais que muitas vezes estavam economicamente bem mais avançados do que ela? $\mathrm{O}$ problema do Estado - e não me refiro apenas ao poder militar estatal ainda está na ordem do dia como um ponto relevante não só para questões explicitamente históricas ${ }^{12}$, mas para os acontecimentos de nossa época.

Quando falamos de "estruturas estatais encaixadas" socialmente ${ }^{13}$, temos de nos perguntar como os Estados foram capazes de construir algum tipo de consenso com atores (coletivos) da sociedade civil e por que esse projeto falhou tantas vezes em muitas regiões do mundo. Certamente não é por acaso que alguns pesquisadores de sociologia histórica (embora não diretamente ligados ao paradigma das "múltiplas modernidades") estão atualmente começando a estudar sistematicamente o Estado na América Latina e sua gênese no século XIX, uma vez 
que essa análise poderia inclusive responder a algumas perguntas relacionadas com o desenvolvimento econômico ${ }^{14}$.

Estou convencido de que é possível e necessário associar mais estreitamente a tese das "múltiplas modernidades" com as reflexões sobre o papel do Estado, seja na atualidade, seja há alguns séculos. Um debate mais centrado na política (melhor dizendo, centrado no Estado) acerca das múltiplas modernidades poderia nos levar a entender por que, no mundo contemporâneo, somente determinadas regiões são bem-sucedidas na competição econômica mundial. Essa situação, com certeza, não mudou desde os primórdios do capitalismo (qualquer que tenha sido a data inicial) - um sistema que jamais se baseou exclusivamente em uma dialética econômica de meios e fins.

3. Centrar a análise no Estado também é uma oportunidade de observar o capitalismo a partir de um novo ângulo. Está em curso no momento um grande debate sobre os vários capitalismos contemporâneos; mas curiosamente essa abordagem está praticamente esquecida na pesquisa histórico-sociológica atual. Indagar sobre as diversas formas assumidas pelo capitalismo em diferentes regiões do mundo poderia ser bastante fecundo, especialmente porque possibilita relacioná-las com os padrões de colonização européia no mundo não-europeu e com suas conseqüências econômicas. Aliás, não estou certo se a distinção estabelecida por Weber entre o capitalismo "tradicional" (existente na maioria das fases da história mundial) e o capitalismo "moderno" (que, segundo Weber, seria típico da modernidade ocidental) tem muita utilidade nesse sentido. A meu ver, é mais promissor insistir nas distinções introduzidas no debate pelo livro de Wrigley, levando em conta principalmente que idéias semelhantes também podem ser encontradas nos estudos de Fernand Braudel, que sempre se interessou pela diferenciação de tipos de trocas de mercado [market exchange] (cf. Braudel, 1985 e outros). A distinção que Braudel estabelece entre a esfera da vida material, as trocas de mercado e o capitalismo não é de modo algum a última palavra no debate. Mas é no mínimo estimulante ver que alguns autores situados no centro do debate sobre as "múltiplas modernidades" começaram a lidar com esse problema (Arnason, 2002).

4. Tudo isso somado, ainda não resolvi se é melhor falar de civilizações ou de subunidades de civilizações. Pomeranz (2000:6 e ss.), entre outros, chama a atenção para um pressuposto demasiado freqüente nas análises comparativas de civilizações: o de que há uma estranha espé- 
cie de identidade entre os países europeus, isto é, a tendência a descrever a ascensão industrial da Inglaterra como a decolagem industrial de toda a Europa. Isso é muito questionável. Ninguém sabe ao certo se a ascensão da Europa Ocidental teria ocorrido se outro país que não a Inglaterra - por uma série de causas, inclusive aleatórias - tivesse dado esse salto anteriormente. Assim, ainda não está claro como devemos comparar o peso de padrões civilizacionais entre diferentes países ou regiões. Resumindo o argumento: é preciso avaliar cuidadosamente se é de fato necessário adotar uma abordagem civilizacional abrangente para explicar a divergência de caminhos para a modernidade entre a Europa e a China, ou se é melhor subdividir essas civilizações e fazer comparações menos ambiciosas entre unidades menores - regiões ou Estados-nações, por exemplo. Esse último enfoque, repito, também abre a possibilidade de tratar de modo mais convincente o problema do pequeno número de casos.

5. Parece-me ser necessário focalizar de modo muito mais sistemático, por um lado, os acontecimentos contingentes, e, por outro, as estruturas e processos altamente estáveis. Essa observação toca vagamente no segundo argumento aqui mencionado, em que afirmei que as análises de civilizações deveriam ater-se aos últimos dois séculos se realmente visam à explicação de caminhos divergentes. O que une essas duas idéias, porém, é o fato de os pesquisadores precisarem estar conscientes da possibilidade de haver acontecimentos inexplicáveis que poderiam direcionar a história para trilhas inesperadas. Por isso, deveria haver uma cooperação mais estreita entre os estudiosos da macrossociologia ligados ao debate das "múltiplas modernidades" e os neo-institucionalistas. A razão disso é que os neo-institucionalistas já começaram a tratar historicamente a questão de por que certas estruturas são altamente estáveis enquanto outras são mutáveis e voláteis, suscetíveis à influência de acontecimentos contingentes (Thelen, 2003). Tenho certeza de que apenas esse tipo de argumento poderá dar fundamentos sólidos à teoria das "múltiplas modernidades". Enquanto os teóricos dessa tese não tiverem argumentos plausíveis e convincentes para explicar por que um determinado caminho seguido por subunidades de uma civilização (Estado-nação, região etc.) não muda com facilidade, em função exatamente de determinadas limitações civilizacionais, o paradigma continuará a ser alvo de intenso bombardeio crítico - e com justa razão! Somente se houver alguma noção teórica de como um tipo específico de modernidade se fundamenta em instituições, o paradigma civilizacional ou das "múltiplas modernidades" 
conseguirá suplantar as abordagens macrossociológicas concorrentes. Em qualquer outra situação, os pesquisadores que se mantiverem fiéis a comparações internacionais tradicionais terão bons argumentos para não aderir ao paradigma das "múltiplas modernidades".

Isso me leva novamente a Max Weber e aos clássicos - e às minhas observações finais. Creio que vai se tornar cada vez mais difícil aceitar o aspecto macrossociológico da obra de Weber, pois é bem provável que outros estudos na linha da "escola da Califórnia" venham a ser publicados. Nesse momento, não me parece provável que essa escola de pensamento seja outra vez relegada a um segundo plano, o que significa que os esforços de Weber para explicar a estagnação da Índia e da China e o dinamismo da Europa com base em estruturas e acontecimentos da Idade Média, ou mesmo algumas centenas de anos atrás, tendem a perder credibilidade. A explicação de Weber sobre a ascensão do Ocidente não é mais defensável - por razões empíricas (isto é, históricas) e metodológicas. Mas essa crítica não atinge a avaliação da maior parte de seus instrumentos analíticos e terminológicos. Desse ponto de vista, seus estudos ainda têm grande valor para os pesquisadores da macrossociologia, pois a sua insistência na multicausalidade, sua atenção concreta aos atores (coletivos) e às instituições societárias (Kalberg, 1994) podem nos dar muitas indicações sobre o modo de estruturar argumentos macrossociológicos sem o risco de cairmos nas armadilhas do reducionismo.

(Recebido para publicação em junho de 2005)

(Versão definitiva em fevereiro de 2006)

\section{NOTAS}

1. A referência a esses livros não deve fazer esquecer que nesse ínterim alguns dos autores mudaram de posição, às vezes de maneira importante, no debate sobre a "ascensão do Ocidente": Eric L. Jones (1988) e John A. Hall (2004), por exemplo, parecem hoje muito mais cautelosos na explicação dessa ascensão em virtude das evidências históricas agora disponíveis.

2. Além disso, não se deve esquecer que há muito ceticismo, especialmente entre os historiadores, quanto à possibilidade metodológica de fazer "comparações totais" entre civilizações (cf. Osterhammel, 2001). 
3. Ver, por exemplo, a explicação histórica ou etnológica de Fischer (1989); para uma abordagem mais sociológica, Knöbl (2006).

4. Na opinião de Perry Anderson (1994), é impossível negar que o termo "região" possui muitas conotações políticas, mas isso também é verdade no que respeita ao termo "civilização", que está longe de ser uma noção "inocente". Contudo, se a maioria dos autores define "civilização" quase exclusivamente em função da cultura e/ou da religião, o mesmo não se pode dizer do termo "região", pois os economistas o utilizam tanto quanto os historiadores e os geógrafos, o que sugere a multidimensionalidade potencial dessa noção.

5. Contudo, a literatura sobre as "múltiplas modernidades" inclui algumas tendências ao desistoricizar a noção de civilização justamente para livrá-la de uma definição excessivamente culturalista. Assim, Randall Collins tentou definir civilizações como "zonas de prestígio": "Ao contrário, o conceito de civilização como uma zona de prestígio dirige a atenção a uma atividade social e a uma variação cultural. Uma zona civilizacional possui centros; floresce e desaparece à medida que nela se realizam atividades que promovem seu magnetismo. As civilizações não são estáticas, mas ativas; nos termos da sociologia de Durkheim, elas se constroem em torno de lugares onde se desenvolvem rituais sociais de elevado grau de intensidade, gerando assim energia emocional e carisma social. [...] A outra vantagem de lidar com zonas de prestígio civilizacional em vez de códigos culturais é compreender que uma civilização geralmente se constitui mediante uma diversidade de padrões culturais. Por serem centros de criatividade, as civilizações normalmente são modeladas através da história por posições rivais" (Collins, 2004:133).

6. De maneira análoga, Gregory Melleuish afirma que as civilizações são difíceis de definir porque geralmente são entidades muito grandes e amorfas, que se modificam com o tempo e contêm várias unidades complexas, as quais conseguem criar por si sós diversas possibilidades históricas de "desenvolvimento" (Melleuish, 2004:235). Cf. as diversas contribuições ao livro de Arnason, Eisenstadt e Wittrock, que penam para definir esses marcos axiais. Eisenstadt (2005) prefere agora falar em "complexos axiais" (e não mais em "era axial"), Wittrock (2005) afirma que é preciso levar em consideração pelo menos cinco diferentes trajetórias para a era axial, o que torna o conceito ainda mais difuso do que na década de 1970, quando Eisenstadt deu início ao seu projeto de teorização da era axial.

7. “A principal característica da economia baseada no mineral foi sua capacidade de libertar a produção da dependência da produtividade da terra [...]" (Wrigley, 1988:32).

8. A opinião de Blaut também é diferente da de Wong e de Pomeranz, porque ele fixa a data do desvio de rumos entre a Europa e a Ásia em um período histórico muito anterior, decisão perfeitamente compatível com suas premissas de que o colonialismo foi um dos principais fatores da acumulação de capital.

9. Isso nos traz de volta ao centro do debate sobre as "verdadeiras" razões da decolagem industrial da Europa/Inglaterra. Já afirmei que ainda não há solução para esse debate e, com certeza, nenhum consenso se formou - fora o fato de que a maioria dos observadores admite que, na busca de causas, não se deve focalizar a Europa e/ ou a Ásia, mas a Inglaterra e determinadas regiões da China (como o vale do rio Yangzi). Jack Goldstone (1987), um dos mais experientes sociólogos envolvidos no debate, já formulou há tempos uma espécie de explicação cultural e tecnológica. Pelo menos desde a década de 1980, Goldstone atribuiu a uma cultura científica e técnica especi- 
ficamente inglesa (não européia) a viabilização da invenção de tecnologias que acabaram permitindo evitar o ciclo econômico malthusiano. Ver também Goldstone (2002).

10. Veja também as contribuições de um dos mais proeminentes antropólogos da atualidade: Jack Goody $(1996 ; 2004)$.

11. Uma das razões desse esquecimento está com certeza ligada ao fato de que os debates sobre a posição da América Latina se deram no âmbito da teoria dos sistemas mundiais ou da teoria da dependência. Visto que ambas tendem a diminuir a importância de momentos culturais tão relevantes para a maioria dos autores que defendem o paradigma das "múltiplas modernidades", é perfeitamente compreensível que poucos desses autores ousem penetrar no campo dos estudos latino-americanos.

12. Cabe notar que os autores da chamada "escola da Califórnia", antes citada, dispõem-se a discutir outros fatores além dos econômicos. R. Bin Wong, por exemplo, afirma com todas as letras que os processos de construção do Estado e do Império seguiram rumos completamente diferentes na Europa e na China. Ver Wong (1997, esp. pp. 77 e ss.).

13. Cf. Evans (1995). Sem dúvida, a questão do "encaixe" [embeddedness] esteve e ainda está presente no centro das preocupações dos analistas dos processos de modernização (cf. Davis, 2004).

14. Veja, por exemplo, o estudo de Miguel Angel Centeno (2002) que destaca a ocorrência na América Latina do século XIX de um tipo diferente de contendas armadas, que não levou à formação das mesmas estruturas estatais existentes na Europa Ocidental, resultando em uma fragmentação do Estado na região. Veja a mesma questão interpretada por uma ótica distinta em James Mahoney (2003).

\section{REFERÊNCIAS BIBLIOGRÁFICAS}

ABU-LUGHOD, Janet L. (1989), Before European Hegemony. The World System A.D. 1250-1350. New York/Oxford, Oxford University Press.

ANDERSON, Perry. (1994), “The Invention of the Region 1945-1990". Working Paper, no 94-2, European University Institute/European Forum.

ARNASON, Johann P. (2002), The Peripheral Centre. Essays on Japanese History and Civilization. Melbourne, Trans Pacific Press.

(2004), “Civilizational Patterns and Civilizing Processes", in S. A. Arjomand e E. A. Tiryakian (orgs.), Rethinking Civilizational Analysis. London, Sage, pp. 103-118.

BLAUT, J. M. (1993), The Colonizer's Model of the World. Geographical Diffusionism and Eurocentric History. New York/London, Guilford Press.

BRAUDEL, Fernand. (1985), Sozialgeschichte des 15.-18. Jahrhunderts. Munich, Kindler Verlag (3 vols.) 
CENTENO, Miguel Angel. (2002), Blood and Debt. War and the Nation-State in Latin America. Pennsylvania, University Park, Pennsylvania State University Press.

COLLINS, Randall. (2004), "Civilizations as Zones of Prestige and Social Contact", in S. A. Arjomand e E. A. Tiryakian (orgs.), Rethinking Civilizational Analysis. London, Sage, pp. 132-147.

CONRAD, Sebastian e RANDERIA, Shalini. (2002), “Einleitung. Geteilte Geschichten Europa in einer postkolonialen Welt", in S. Conrad e S. Randeria (orgs.), Jenseits des Eurozentrismus. Postkoloniale Perspektiven in den Geschichts- und Kulturwissenschaften. Frankfurt/New York, Campus Verlag, pp. 9-49.

DAVIS, Diane. (2004), Discipline and Development. Middle Classes and Prosperity in East Asia and Latin America. Cambridge, Cambridge University Press.

EISENSTADT, Shmuel N. (2005), "Axial Civilizations and the Axial Age Reconsidered", in J. P. Arnason, S. N. Eisenstadt e B. Wittrock (orgs.), Axial Civilizations and World History. Boston/Leiden, Brill, pp. 532-564.

EVANS, Peter. (1995), Embedded Autonomy. States and Industrial Transformation. Princeton, Princeton University Press.

FISCHER, David Hackett. (1989), Albion's Seed. Four British Folkways in America. New York/Oxford, Oxford University Press.

FRANK, Andre Gunder. (1998), ReOrient. Global Economy in the Asian Age. Berkeley, Los Angeles/London, University of California Press.

(2004), "Geschichtswissenschaft und Sozialtheorie Re-Orientieren”. Zeitschrift für Weltgeschichte, vol. 5, pp 9-41.

GOLDSTONE, Jack A. (1987), “Cultural Orthodoxy, Risk, and Innovation: The Divergence of East and West in the Early Modern World". Sociological Theory, vol. 5, pp. 119-135.

(2000), "The Rise of the West - or Not? A Revision to Socio-economic History". Sociological Theory, vol. 18, no 2, pp. 175-194.

. (2002), "Efflorescences and Economic Growth in World History: Rethinking the 'Rise of the West' and the Industrial Revolution". Journal of World History, vol. 13, no 2, pp. 323-389.

GOODY, Jack. (1996), The East in the West. Cambridge, Cambridge University Press. . (2004), Capitalism and Modernity. The Great Debate. Cambridge, Polity Press.

HALL, John A. (1985), Powers and Liberties. The Causes and Consequences of the Rise of the West. Berkeley, Basil Blackwell.

(2004), "Confessions of a Eurocentric", in S. A. Arjomand e E. A. Tiryakian (orgs.), Rethinking Civilizational Analysis. London, Sage, pp. 192-200.

HARTZ, Louis. (1964), The Founding of New Societies. Studies in the History of the United States, Latin America, South Africa, Canada, and Australia. New York, Harcourt Brace Jovanovich.

HOBSON, John M. (2004), The Eastern Origins of Western Civilisation. Cambridge, Cambridge University Press. 
JONES, Eric L. (1981), The European Miracle: Environments, Economics, and Geopolitics in the History of Europe and Asia. Cambridge, Cambridge University Press.

(1988), Growth Recurring. Economic Change in World History. Oxford, Clarendon Press.

KALBERG, Stephen. (1994), Max Weber's Comparative-Historical Sociology. Cambridge, Polity Press.

KING, Gary, KEOHANE, Robert O. e VERBA, Sidney. (1994), Designing Social Inquiry. Scientific Inference in Qualitative Research. Princeton, Princeton University Press.

KNÖBL, Wolfgang. (2006), “Verwerfungen in der klassischen Moderne - der US-amerikanische Süden als Problemfall in der Debatte um die 'Multiple Modernities'”, in T. Schwinn (org.), Die Vielfalt und Einheit der Moderne. Opladen, Verlag für Sozialwissenschaften.

LANDES, David. (1998), The Wealth and Poverty of Nations. Why Some Are so Rich and Some so Poor. New York, W.W. Norton \& Company.

LIEBERSON, Stanley. (1991), "Small N's and Big Conclusions: An Examination of the Reasoning in Comparative Studies Based on a Small Number of Cases". Social Forces, vol. 70, no 1, pp. 307-320.

LIJPHART, Arend. (1971), "Comparative Politics and the Comparative Method". The American Political Science Review, vol. LXV, pp. 682-693.

MAGUBANE, Zine. (2005), “Overlapping Territories and Intertwined Histories: Historical Sociology's Global Imagination", in J. Adams, E. S. Clemens e A. S. Orloff (orgs.), Remaking Modernity. Politics, History, and Sociology. Durham/London, Duke University Press, pp. 92-108.

MAHONEY, James. (2003), "Long-Run Development and the Legacy of Colonialism in Spanish America". American Journal of Sociology, vol. 109, no 1, pp. 50-106.

MELLEUISH, Gregory. (2004), “The Clash of Civilizations. A Model of Historical Development?", in S. A. Arjomand e E. A. Tiryakian (orgs.), Rethinking Civilizational Analysis. London, Sage, pp. 234-244.

MITTERAUER, Michael. (2003), Warum Europa? Mittelalterliche Grundlagen eines Sonderwegs. Munich, C.H. Beck Verlag.

OSTERHAMMEL, Jürgen. (1998), Die Entzauberung Asiens. Europa und die asiatischen Reiche im 18. Jahrhundert. Munich, C.H. Beck Verlag.

. (2000), Sklaverei und die Zivilisation des Westens. Munich, Carl Friedrich von Siemens Stiftung.

. (2001), "Transnationale Gesellschaftsgeschichte: Erweiterung oder Alternative". Geschichte und Gesellschaft, vol. 27, no 3, pp. 464-479.

POMERANZ, Kenneth. (2000), The Great Divergence. China, Europe and the Making of the Modern World Economy. Princeton, Princeton University Press.

SZÜCS, Jenö. (1988), “Three Historical Regions of Europe. An Outline”, in J. Keane (org.), Civil Society and the State. New European Perspectives. London/New York, Verso, pp. 291-332. 


\section{Wolfgang Knöbl}

TENBRUCK, Friedrich. (1992), “Was war der Kulturvergleich, ehe es den Kulturvergleich gab?", in J. Matthes (org.), Zwischen den Kulturen? Die Sozialwissenschaften vor dem Problem des Kulturvergleichs. Göttingen, Verlag Otto Schwartz \& Co, pp. 13-35.

THELEN, Kathleen. (2003), “How Institutions Evolve. Insights from Comparative Historical Analysis", in James R. Mahoney e D. Rueschemeyer (orgs.), Comparative Historical Analysis in the Social Sciences. Cambridge, Cambridge University Press, pp. 208-240.

TOWNSEND, Camilla. (2000), Tales of Two Cities. Race and Economic Culture in Early Republican North and South America: Guayaquil, Ecuador, and Baltimore. Austin, University of Texas Press.

TYRRELL, Ian. (2002), “Beyond the View from Euro-America. Environment, Settler Societies, and the Internalization of American History", in T. Bender (org.), Rethinking American History in a Global Age. Berkeley/Los Angeles/London, University of California Press, pp. 168-191.

WAGNER, Peter. (2005), "Palomar's Questions, the Axial Age Hypothesis, European Modernity and Historical Contingency", in J. P. Arnason, S. N. Eisenstadt e B. Wittrock (orgs.), Axial Civilizations and World History. Boston/Leiden, Brill, pp. 86-106.

WEBER, Max. (1951), The Religion of China. New York, Free Press.

WERNER, Michael e ZIMMERMANN, Bénédicte. (2002), “Vergleich, Transfer, Verflechtung. Der Ansatz der Histoire croisée und die Herausforderung des Transnationalen". Geschichte und Gesellschaft, vol. 28, pp. 607-636.

WITTROCK, Björn. (2005), “The Meaning of the Axial Age”, in J. P. Arnason, S. N. Eisenstadt e B. Wittrock (orgs.), Axial Civilizations and World History. Boston/Leiden, Brill, pp. 52-85.

WONG, R. Bin. (1997), China Transformed. Historical Change and the Limits of European Experience. Ithaca/London, Cornell University Press.

WRIGLEY, E. A. (1988), Continuity, Chance and Change. The Character of the Industrial Revolution in England. New York, Cambridge University Press. 


\section{ABSTRACT}

Max Weber, Multiple Modernities and the Re-Orientation of Social Theory

The debate on "multiple modernities" has focussed till so far either on finding plausible contrasts between different paths into modernity or on theorizing concepts like civilization, region etc. What is missing, however, is a systematic methodological discussion of how to compare different civilizations in the face of the so-called Small N-problem. This problem is the more pressing the better historical-sociological research on Asia and Europe shows how contingent the so-called Rise of the West actually was. The paper ends with some suggestions about the way how civilizational analysis could deal with these methodological problems and what sociological classics like Max Weber can teach us in this respect.

Key words: Max Weber; social theory; Multiple Modernities; rise of the West; civilizations

\section{RÉSUMÉ}

Max Weber, les Multiples Modernités et la Réorientation de la Théorie Sociologique

Jusqu'à présent, la discussion sur les multiples modernités s'est attardée sur la recherche des contrastes possibles entre, d'un côté, les différentes voies vers la modernité et, de l'autre, les théories et concepts de civilisation, région etc. Il manque pourtant une discussion méthodologique systématique sur la façon de comparer des civilisations différentes face à ce qu'on appelle le Small $\mathrm{N}$-problem (le problème du petit nombre de cas). Ce problème ébranle les meilleures recherches historiques et sociologiques sur l'Asie et l'Europe, montrant que la dite Ascension de l'Occident est assez réduite. Dans cet article, on trouve aussi des suggestions sur la façon de se servir de l'analyse des civilisations afin de travailler ces questions méthodologiques ainsi que des enseignements qu'on peut trouver chez les sociologues classiques tels que Max Weber.

Mots-clé: Max Weber; Théorie Sociologique; Multiples Modernités; ascension de l'Occident; civilisations 